\title{
DETERMINAÇÃO DA ESCALA DE COLORAÇÃO DA CASCA E DO RENDIMENTO EM SUCO DO MARACUJÁ-AMARELO EM DIFERENTES ÉPOCAS DE COLHEITA ${ }^{1}$
}

\author{
THAIS VIANNA SILVA², EDER DUTRADE RESENDE ${ }^{3}$, \\ ALEXANDRE PIO VIANA ${ }^{4}$, SILVIADE MENEZES DE FARIA PEREIRA $^{5}$, \\ LANAMAR DEALMEIDACARLOS ${ }^{6}$, LETÍCIA VITORAZI $^{7}$
}

RESUMO -Este trabalho teve como objetivo determinar uma escala de coloração da casca para identificar o estádio de maturação do maracujá-amarelo e avaliar o rendimento em suco, em diferentes épocas de colheita. Os experimentos foram constituídos de 2 épocas de colheita, contemplando a estação de menor temperatura e menor precipitação de chuvas ( $\mathrm{EP}_{1}$-Maio/Setembro), a estação de maior temperatura e precipitação de chuvas (EP 2 -Outubro/Dezembro) e 7 estádios de maturação, com 10 repetições. Os resultados foram avaliados pelo teste de Tukey, a 5\% de significância. O parâmetro b de Hunter foi utilizado como o indexador da mudança da coloração amarela. Verificou-se que a mudança de coloração ocorreu no sentido da base para o pedúnculo do fruto. Os frutos da época $\mathrm{EP}_{2}$ apresentaram a maior espessura de casca e o menor rendimento em suco, nos estádios iniciais de amadurecimento. Nos frutos com mais de 65,9\% da casca amarelada, a época de colheita não influenciou na espessura da casca e no rendimento em suco, apresentando níveis máximos de suco. Frutos da época EP1 apresentaram o máximo rendimento a partir do estádio com 21,3\% de cor amarela. Termos para indexação: Passiflora edulis f. flavicarpa, cor da casca, rendimento em suco, estádios de maturação.

\section{DETERMINATION OF THE PEEL COLOR SCALE AND JUICE YIELD OF YELLOW PASSION FRUITS IN DIFFERENT HARVEST SEASONS}

ABSTRACT - This work had the aim to determinate the peel color scale intended to identify the ripening stage of the yellow passion fruit and evaluate its juice yield in different harvest seasons. The experiments were constituted of 2 harvest seasons and they were accomplished during the period of low temperatures and less precipitation $\left(\mathrm{EP}_{1}\right.$ - May/September) and high temperatures and more precipitation $\left(\mathrm{EP}_{2}\right.$ - October/December), and seven ripening stages using ten replications. The results were compared by applying the Tukey test at the level of $5 \%$ of probability. Hunter b parameter was used as the yellowing index. It was verified that the yellow color progressed from the base to the fruit peduncle. Fruits from the $\mathrm{EP}_{2}$ season presented the lowest juice yield and the highest peel thickness in the early ripening stages. In fruits with at least $65 \%$ of yellow color peel, the harvest season did not influence in the peel thickness and in the juice yield, showing the highest level of juice. Fruits from the EP1 season showed the higher juice yield after $21,3 \%$ yellow color.

Index terms: Passiflora edulis f. flavicarpa, peel color, juice yield, ripening stages.

\section{INTRODUÇÃO}

A produção mundial de maracujá é estimada em 805.000 t, compreendendo as duas variedades comerciais: maracujá-roxo e maracujá-amarelo. O Brasil e o Equador são responsáveis por cerca de 700.000 t, constituídas basicamente pelo maracujáamarelo (Iti Tropicals, 2008). A produção brasileira de maracujáamarelo em 2004 foi de 491.619 t, em uma área plantada de 37.252 ha (IBRAF, 2008). Essa produção engloba todos os Estados brasileiros e o Distrito Federal, apresentando boas perspectivas para a ampliação da área cultivada. A Bahia destaca-se como o maior produtor, seguido do Espírito Santo, São Paulo, Rio de Janeiro e Sergipe (Hafle et al., 2005).
A colheita do maracujá é feita com os frutos caídos ao solo ou presos nas ramagens da planta, num estádio de maturação em que a casca se encontra com coloração predominantemente amarela. Neste estádio, o fruto é bastante sensível à perda de água, ao murchamento, facilitando a contaminação por microrganismos e contribuindo para diminuir seu período de conservação pós-colheita (Arjona et al., 1992; Durigan, 1998; Marchi et al., 2000).

A mudança na coloração da casca do maracujá, durante o processo de amadurecimento, é o critério mais utilizado pelo consumidor para julgar o grau de maturação do fruto. As alterações na cor estão intrinsecamente relacionadas com as modificações físicas e químicas que acompanham o amadurecimento, sendo usada pelo produtor como indicativo

1(Trabalho 131-07). Recebido em: 21-05-2007. Aceito para publicação em: 12-09-2008.

${ }^{2}$ Eng. Agr., M.Sc. e Doutoranda em Produção Vegetal (UENF/CCTA/LTA), e-mail: tavianna@gmail.com (Avenida Alberto Lamego, 2000. CEP 28013602, Campos dos Goytacazes-RJ.)

${ }^{3}$ Prof. Dr., Laboratório de Tecnologia de Alimentos (LTA/CCTA/UENF), e-mail: eresende@uenf.br (autor para correspondência)

${ }^{4}$ Prof., Dr., Laboratório de Melhoramento Genético Vegetal (UENF/CCTA/LMGV), e-mail: pirapora@uenf.br

${ }^{5}$ Técnica de Nível Superior. D.Sc., Laboratório de Tecnologia de Alimentos (UENF/CCTA/LTA), e-mail: silvia@uenf.br

${ }^{6}$ Técnica de Nível Superior. M.Sc., Laboratório de Tecnologia de Alimentos (UENF/CCTA/LTA), e-mail: lanamar@uenf.br

${ }^{7} \mathrm{IC}$ - CNPq (UENF/CCTA/LTA), e-mail: vitorazi@uenf.br

Rev. Bras. Frutic., Jaboticabal - SP, v. 30, n. 4, p. 880-884, Dezembro 2008 
para a colheita (Gamarra Rojas \& Medina, 1996; Salomão et al., 2001).

A correlação entre a coloração da casca e os estádios de maturação permitirá ao setor produtivo estabelecer um planejamento de colheita a fim de ampliar o período de vida de prateleira e fornecer maracujás que possam satisfazer às exigências do mercado interno e, eventualmente, dos exportadores.

No trabalho de Silva et al. (2005), verificou-se que o maracujá-amarelo apresenta uma evolução da cor amarela no sentido da base para o pedúnculo do fruto, possibilitando a identificação de uma escala de cor para avaliar o processo de amadurecimento do fruto.

Este trabalho teve como objetivo determinar uma escala de coloração da casca para identificar o estádio de maturação do maracujá-amarelo e avaliar o rendimento em suco nas diferentes épocas de colheita

\section{MATERIAL E MÉTODOS}

Foram utilizados frutos de maracujazeiro-amarelo (Passiflora edulis f. flavicarpa Degener), colhidos em campo comercial localizado no município de Campos dos GoytacazesRJ. O solo é do tipo Argissol Amarelo, desenvolvido a partir de sedimentos terciários, horizonte $B$ textural com camada superficial arenosa, e relevo suavemente ondulado que caracterizam bem as condições edáficas do local onde se cultiva essa fruteira, na região norte Fluminense (Carvalho et al., 2000).

Os experimentos foram conduzidos em delineamento inteiramente casualizado, no esquema fatorial $2 \times 7$, constituído de 2 épocas de colheita e 7 estádios de maturação, com 10 repetições dos frutos com o mesmo tempo após a antese. A época de colheita $1\left(\mathrm{EP}_{1}\right)$ compreendeu o período de maio a setembro de 2003 , onde as condições climáticas foram caracterizadas por temperatura média mensal mais amena $\left(20,8 \pm 0,9^{\circ} \mathrm{C}\right)$ e menor precipitação média mensal $(38,7 \pm 33,4 \mathrm{~mm})$. Aépoca de colheita $2\left(\mathrm{EP}_{2}\right)$ foi conduzida entre os meses de outubro e dezembro de 2003 , com temperatura média mensal mais alta $\left(23,4 \pm 1,4^{\circ} \mathrm{C}\right) \mathrm{e}$ maior precipitação média mensal $(47 \pm 77 \mathrm{~mm})$. Os resultados foram interpretados pelo programa GENES (Cruz, 2001), para a comparação entre as médias, utilizando-se do teste de Tukey, ao nível de 5\% de probabilidade.

A amostragem dos frutos, em diferentes estádios de maturação, foi realizada ao longo do período de amadurecimento dos frutos. Cerca de 1.000 flores foram marcadas e polinizadas manualmente. $\mathrm{Na}$ época $\mathrm{EP}_{1}$, a primeira colheita de frutos foi conduzida quando ocorreu uma mudança de luminosidade da casca (64 dias após a antese, DAA), e a última, aos 100 DAA (superfície da casca totalmente amarelada). $\mathrm{Na}$ época $\mathrm{EP}_{2}$, a primeira colheita, conduzida no momento de mudança da luminosidade da casca, foi realizada aos 43 DAA, e a última colheita (frutos maduros) foi feita aos 71 DAA. Na colheita, as amostras foram selecionadas seguindo critérios de homogeneização quanto ao estádio de maturação, definido pela estimativa de área da casca com coloração amarela, uniformidade no tamanho e boas condições fitossanitárias.
Os frutos de aproximadamente $210 \mathrm{~g}$ foram colhidos pela manhã e transportados para o Laboratório de Tecnologia de Alimentos, onde foram lavados e secos.

A coloração da casca foi medida, usando-se o Colorímetro Hunterlab Miniscan Spectrophotometer (MiniScan XE Plus), sendo realizada em quatro pontos eqüidistantes, sobre a região mediana das partes superior (pedúnculo) e inferior (base) dos frutos e caracterizada pelo parâmetro b de Hunter, que avalia as alterações na cor amarela. A mudança na coloração da casca foi identificada também pelos índices de reflectância da luz sobre a casca, em diferentes comprimentos de onda do espectro de luz visível.

Neste trabalho, identifica-se uma escala de maturação do maracujá com base em sete intensidades de cor amarela na casca do fruto, sendo comum às duas épocas de colheita. Essa escala é baseada no incremento dos valores médios do parâmetro $b$ de Hunter, na região superior do fruto, caracterizada por apresentar menores valores desse parâmetro em relação à região inferior (Silva et al., 2005). A escala foi obtida a partir dos valores médios do parâmetro b de Hunter, calculando a diferença entre as determinações médias da cor em cada estádio de maturação e o estádio verde inicial, dividindo-se pela variação total do parâmetro de cor amarela ao longo do processo de amadurecimento do fruto.

Os frutos foram cortados na região equatorial, para a retirada da polpa bruta (resíduos + suco). A espessura da casca foi medida em quatro pontos eqüidistantes na região equatorial. Após a extração e pesagem da polpa bruta, ela foi processada no homogeneizador Arno (módulo "pulsar") e filtrada em tela filó (1 $\mathrm{mm}$ ) com auxílio de espremedor manual, o que permitiu a separação do suco e do resíduo da polpa, arilo e sementes. O rendimento em suco foi expresso em percentagem da massa total do fruto através da seguinte fórmula:

Rendimento em suco $(\%)=\frac{\text { Massa da polpa bruta }(\mathrm{g})-\text { Massa do resíduo }(\mathrm{g})}{\text { Massa total do fruto }(\mathrm{g})} \times 100$

\section{RESULTADOS E DISCUSSÃO}

Os resultados das leituras do parâmetro b de Hunter na casca do maracujá-amarelo, realizadas nas regiões superior e inferior do fruto, em duas épocas de colheita, estão apresentados na Tabela 1. A análise estatística dos dados confirmou a igualdade de cor entre as regiões similares dos frutos, independentemente da época de colheita. No entanto, a evolução da coloração da casca durante a maturação ocorreu de forma diferenciada entre as duas regiões, sendo que a região inferior amarelou mais rapidamente, conforme relatado por Silva et al. (2005). Dessa forma, a escala de cor pode ser identificada para uma região específica do fruto, podendo, contudo, ser obtida através do somatório dos valores das leituras de cor das regiões superior e inferior para representar toda a superfície.

Os índices médios de reflectância da casca dentro do espectro de comprimento de onda da luz visível, nas regiões superior e inferior do fruto, em diferentes estádios de maturação 
e épocas de colheita do maracujá, podem ser observados na Figura 1. O incremento de cor amarela em função dos estádios de maturação dos frutos pode ser identificado pelo aumento dos índices de reflectância, na faixa de comprimento de onda que contempla a mudança das tonalidades verdes para tonalidades amareladas. No início do amadurecimento, notam-se os maiores índices de reflectância da casca no intervalo de comprimento de onda para tonalidades esverdeadas, onde o índice máximo de reflectância na região superior do fruto foi da ordem de $15 \%$. Os índices de reflectância atingem limites próximos a 70\%, quando os frutos se encontram totalmente amarelos. Este incremento dos índices de reflectância representativos de tonalidades amarelas é correlacionado com o parâmetro b de Hunter, que possibilita a caracterização da escala de cor dos frutos. A padronização da cor para cada estádio de maturação, nas duas épocas de colheita, pode ser observada nas Figuras 1.a e 1.b, onde as curvas representativas dos índices de reflectância mostram magnitudes de valores muito próximas quando se comparam as duas épocas de colheita.

Na Figura 1, nota-se a ocorrência de maiores índices de reflectância na região inferior do fruto, em todos os estádios de maturação, confirmando que a casca amareleceu no sentido da base para o pedúnculo. Verifica-se também que as maiores diferenças entre os índices de reflectância da casca, para as duas regiões do fruto, ocorreram nos estádios intermediários de maturação (Figura 1.a), devido à irregularidade na mudança de cor entre as duas regiões do fruto. Nos frutos maduros, a diferença entre os perfis de reflectância da casca, nas duas regiões do fruto, foi minimizada devido à distribuição regular da coloração amarela por toda a superfície.

Considerando que a distribuição da cor amarela em toda a superfície do fruto ocorre irregularmente no sentido da base para o pedúnculo, definiu-se a região superior próxima ao pedúnculo para se caracterizar a coloração típica de cada estádio de maturação do maracujá-amarelo. A evolução da cor amarela, nessa região, permitiu a determinação de uma escala de cor contemplando sete estádios de maturação comuns às diferentes épocas de colheita.

A escala de cor foi desenvolvida com base nas médias de leitura do parâmetro $b$ de Hunter da região superior do fruto. Os valores foram padronizados para sete estádios de maturação comuns aos frutos colhidos nas duas épocas de produção (Tabela 2). A padronização da escala de cor comum às duas épocas de colheita pode ser observada na Figura 2. A análise estatística dos resultados, para a região superior do fruto, confirmou a igualdade entre os parâmetros de cor de cada estádio de maturação, nas duas épocas de colheita (Tabela 1). Isto possibilitou uma avaliação mais precisa do efeito da época de colheita e do estádio de maturação sobre as características físicas dos frutos.

Os dados referentes à massa e ao diâmetro equatorial em função dos estádios de maturação, dentro de cada época de colheita, estão apresentados na Tabela 3. Somente os frutos colhidos nos estádios de maturação 2 e 3 , na época $\mathrm{EP}_{2}$, apresentaram menor tamanho do que os colhidos na época $\mathrm{EP}_{1}$. Essa pequena diferença de tamanho dos frutos ocorreu devido à variabilidade genética do maracujá, conforme descrito por Gamarra Rojas \& Medina (1995).

Os frutos colhidos na época $\mathrm{EP}_{2}$, caracterizada por maior temperatura e maior índice pluviométrico do que a época $\mathrm{EP}_{1}$, apresentaram casca mais espessa, entre os estádios de maturação 1 (verde) e 4 (28,5\% cor amarela). Nos estádios de maturação 2 e 3 , os frutos da época $\mathrm{EP}_{1}$ foram maiores, e isto, conseqüentemente, contribuiu para minimizar as diferenças de espessura de casca dos frutos entre as duas épocas de colheita. Verificou-se também que a espessura da casca se reduz com o processo de amadurecimento do fruto (Tabela 3).

Segundo Nascimento et al. (1999), os frutos colhidos em safras de maior regime de chuvas apresentam maior espessura de casca devido à capacidade de retenção de água pela casca. No entanto, no presente experimento, somente se observou esse efeito nos estádios iniciais de amadurecimento (Tabela 3 ).

$\mathrm{Na}$ Tabela 3, nota-se que as medidas de rendimento em suco foram inversamente proporcionais às medidas de espessura da casca, conforme observado também por Nascimento et al. (1999). Verifica-se que, nos estádios de maturação 3 e 4, os frutos da época $\mathrm{EP}_{2}$ apresentaram menor rendimento em suco e maior espessura de casca. Nos frutos mais verdes, observou-se somente uma tendência de menor rendimento para esta época, quando comparada com a época $\mathrm{EP}_{1}$, que apresentou frutos com menor espessura de casca. Os frutos colhidos com mais de 65\% de coloração amarela da casca não apresentaram diferenças de rendimento entre as duas épocas de colheita

No trabalho de Nascimento et al. (1999), os frutos foram amostrados após a abscisão natural e, desta forma, apresentam variabilidade de formato, tamanho e estádio de maturação. Nestas condições, foi verificado que existe um efeito de época de produção sobre o rendimento em suco. Entretanto, na Tabela 3, observa-se que o efeito significativo da época de produção sobre o rendimento em suco ocorreu somente em frutos no estádio de maturação com menos de $65 \%$ de área da casca amarelada, em condições que geralmente antecedem a abscisão natural dos frutos.

A diversidade de formato e tamanho pode influenciar na determinação da espessura de casca e no rendimento em suco, conforme observado por Akamine et al. (citado por Nascimento, 1999). No entanto, Oliveira et al. (citado por Nascimento et al., 1999) observam que o rendimento em suco não mostra correlação com o tamanho do fruto. No atual trabalho, a uniformização do estádio de maturação, formato e tamanho do fruto evidenciou que a época de colheita não influenciou no rendimento em suco de frutos colhidos com pelo menos $65,9 \%$ de área da casca amarelada (Tabela 3 ).

Os maracujás utilizados neste trabalho foram uniformizados com um padrão maior que $200 \mathrm{~g}$ (Tabela 3). Isto pode ter influenciado no alto rendimento em suco, alcançando índices superiores a $40 \%$. No caso da época $\mathrm{EP}_{1}$, altos valores de rendimento foram alcaçados mais cedo, em frutos com $21,3 \%$ de área superficial amarelada. 
TABELA 1- Médias do parâmetro b de Hunter para a região superior (RS) e região inferior (RI) do maracujá-amarelo, em duas épocas de produção ${ }^{1}$ e diferentes estádios de maturação ${ }^{2}$.

\begin{tabular}{ccccccccc}
\hline $\begin{array}{c}\text { Região } \\
\text { de leitura }\end{array}$ & & 1 & 2 & 3 & 4 & 5 & 6 & 7 \\
\hline $\mathrm{RS}$ & $\mathrm{EP}_{1}$ & $10,94 \mathrm{Ad}$ & $11,28 \mathrm{Ad}$ & $15,65 \mathrm{Ac}$ & $17,99 \mathrm{Ac}$ & $26,33 \mathrm{Ab}$ & $29,18 \mathrm{Ab}$ & $36,03 \mathrm{Aa}$ \\
& $\mathrm{EP}_{2}$ & $9,44 \mathrm{Ae}$ & $11,39 \mathrm{Ae}$ & $14,55 \mathrm{Ad}$ & $15,78 \mathrm{Ad}$ & $25,68 \mathrm{Ac}$ & $32,28 \mathrm{Ab}$ & $36,54 \mathrm{Aa}$ \\
\hline $\mathrm{RI}$ & $\mathrm{EP}_{1}$ & $12,57 \mathrm{Ad}$ & $13,98 \mathrm{Ad}$ & $19,11 \mathrm{Ac}$ & $21,92 \mathrm{Ac}$ & $28,39 \mathrm{Ab}$ & $31,66 \mathrm{Ab}$ & $35,19 \mathrm{Aa}$ \\
& $\mathrm{EP}_{2}$ & $11,78 \mathrm{Ac}$ & $12,68 \mathrm{Ac}$ & $16,37 \mathrm{Ac}$ & $17,16 \mathrm{Bc}$ & $29,33 \mathrm{Ab}$ & $32,83 \mathrm{Aab}$ & $35,52 \mathrm{Aa}$
\end{tabular}

Médias seguidas das mesmas letras maiúsculas nas colunas e minúsculas nas linhas não diferem significativamente entre si, pelo teste de Tukey, a 5\% de probabilidade. ( ${ }^{1}$ Época $\mathrm{EP}_{1}$ - Maio/Setembro e Época $\mathrm{EP}_{2}$ - Outubro/Dezembro, ${ }^{2}$ Tabela 2)

TABELA 2 - Escala de cor da casca para sete estádios de maturação do maracujá-amarelo em duas épocas de produção. Campos dos Goytacazes-RJ (2003). Padrões de cor relativos à leitura do parâmetro b de Hunter na região superior do fruto.

\begin{tabular}{cl}
\hline $\begin{array}{c}\text { Estádios de } \\
\text { Maturação }\end{array}$ & \multicolumn{1}{c}{ Escala de cor da casca } \\
\hline 1 & $\begin{array}{l}\text { Frutos de coloração predominante verde (0\% de cor amarela) com } \\
\text { algumas manchas brancas na área superficial da casca }\end{array}$ \\
2 & Frutos com $4,7 \%$ da área superficial da casca amarelada \\
3 & Frutos com $21,3 \%$ da área superficial da casca amarelada \\
4 & Frutos com $28,5 \%$ da área superficial da casca amarelada \\
5 & Frutos com $65,9 \%$ da área superficial da casca amarelada \\
6 & Frutos com $82,4 \%$ da área superficial da casca amarelada \\
7 & Frutos com $100 \%$ da área superficial da casca amarelada \\
\hline
\end{tabular}

TABELA 3 - Médias de massa (M), diâmetro equatorial (DE), espessura da casca (EC) e rendimento em suco (RS) do maracujá-amarelo, em duas épocas de produção ${ }^{1}$ (Época $\mathrm{EP}_{1}$-Maio/Setembro e Época $\mathrm{EP}_{2}$-Outubro/Dezembro), nos diferentes estádios de maturação².

\begin{tabular}{ccccccccc}
\hline & & \multirow{2}{*}{1} & 2 & 3 & 4 & 5 & 6 & 7 \\
\hline $\mathrm{M}(\mathrm{g})$ & $\mathrm{EP}_{1}$ & $214,49 \mathrm{Aa}$ & $239,57 \mathrm{Aa}$ & $238,82 \mathrm{Aa}$ & $228,92 \mathrm{Aa}$ & $215,58 \mathrm{Aa}$ & $202,47 \mathrm{Aa}$ & $221,11 \mathrm{Aa}$ \\
& $\mathrm{EP}_{\mathbf{2}}$ & $225,92 \mathrm{Aa}$ & $200,32 \mathrm{Ba}$ & $206,79 \mathrm{Ba}$ & $210,23 \mathrm{Aa}$ & $212,55 \mathrm{Aa}$ & $206,80 \mathrm{Aa}$ & $207,97 \mathrm{Aa}$ \\
\hline $\mathrm{DE}(\mathrm{mm})$ & $\mathrm{EP}_{\mathbf{1}}$ & $76,59 \mathrm{Aa}$ & $80,68 \mathrm{Aa}$ & $81,31 \mathrm{Aa}$ & $79,5 \mathrm{Aa}$ & $78,23 \mathrm{Aa}$ & $77,94 \mathrm{Aa}$ & $78,03 \mathrm{Aa}$ \\
& $\mathrm{EP}_{\mathbf{2}}$ & $76,14 \mathrm{Aab}$ & $72,56 \mathrm{Bb}$ & $76,18 \mathrm{Bab}$ & $76,48 \mathrm{Aab}$ & $76,98 \mathrm{Aab}$ & $79,38 \mathrm{Aa}$ & $76,68 \mathrm{Aab}$ \\
\hline $\mathrm{EC}(\mathrm{mm})$ & $\mathrm{EP}_{1}$ & $5,79 \mathrm{Abc}$ & $7,23 \mathrm{Aa}$ & $6,69 \mathrm{Aab}$ & $6,17 \mathrm{Aabc}$ & $6,01 \mathrm{Aabc}$ & $5,48 \mathrm{Abc}$ & $4,85 \mathrm{Ac}$ \\
& $\mathrm{EP}_{\mathbf{2}}$ & $8,28 \mathrm{Ba}$ & $7,87 \mathrm{Aab}$ & $6,87 \mathrm{Aabc}$ & $7,78 \mathrm{Bab}$ & $6,46 \mathrm{Abcd}$ & $5,35 \mathrm{Acd}$ & $5,02 \mathrm{Ad}$ \\
\hline $\mathrm{RS}(\%)$ & $\mathrm{EP}_{\mathbf{1}}$ & $35,66 \mathrm{Aab}$ & $31,44 \mathrm{Ab}$ & $38,33 \mathrm{Aab}$ & $40,04 \mathrm{Aa}$ & $41,28 \mathrm{Aa}$ & $40,44 \mathrm{Aa}$ & $40,16 \mathrm{Aa}$ \\
& $\mathrm{EP}_{\mathbf{2}}$ & $33,50 \mathrm{Aabc}$ & $29,03 \mathrm{Ac}$ & $32,25 \mathrm{Bbc}$ & $32,08 \mathrm{Bbc}$ & $38,91 \mathrm{Aab}$ & $39,65 \mathrm{Aab}$ & $41,40 \mathrm{Aa}$
\end{tabular}

Médias seguidas das mesmas letras maiúsculas nas colunas e minúsculas nas linhas não diferem significativamente entre si, pelo teste de Tukey, a $5 \%$ de probabilidade. ('Época $\mathrm{EP}_{1}$ - Maio/Setembro e Época $\mathrm{EP}_{2}$ - Outubro/Dezembro, ${ }^{2}$ Tabela 2)
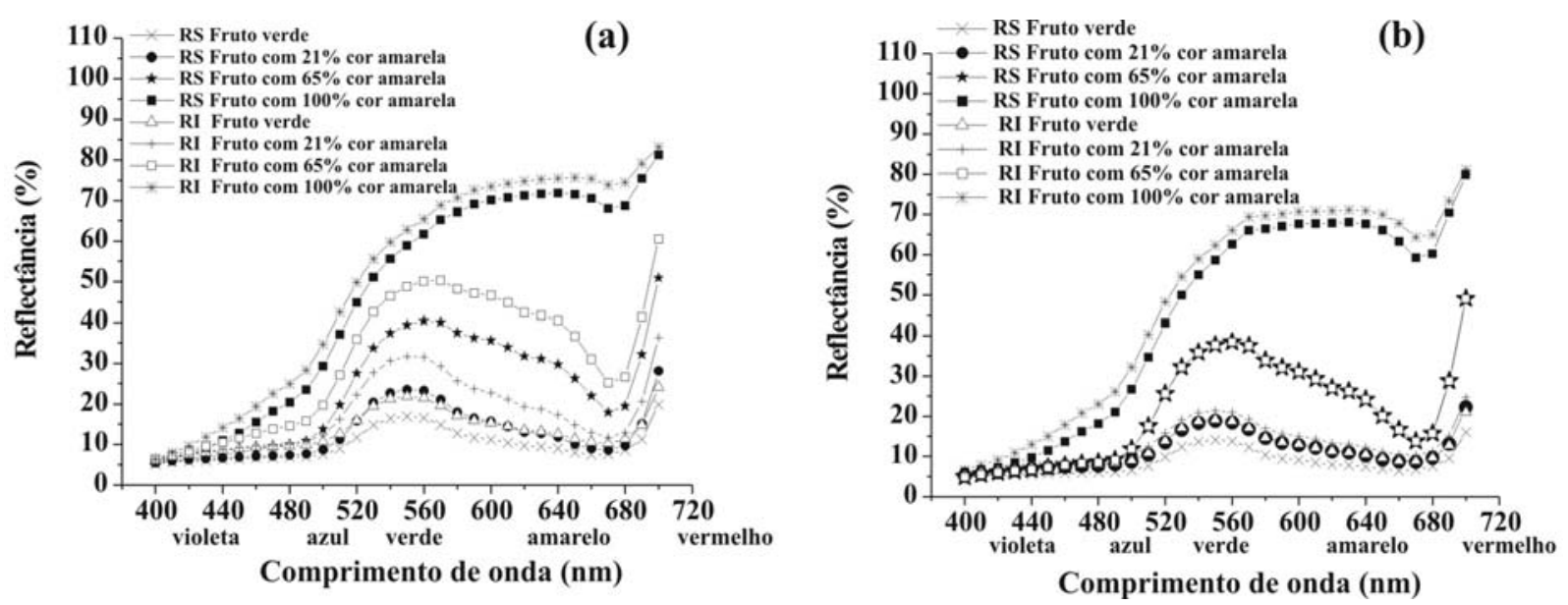

FIGURA 1- Índices de reflectância da casca na região superior (RS) e região inferior (RI) do maracujá-amarelo, em função do comprimento de onda, durante o amadurecimento dos frutos, em duas épocas de produção: Época EP - Maio/Setembro (a) e Época $\mathrm{EP}_{2}$ - Outubro/Dezembro (b). 


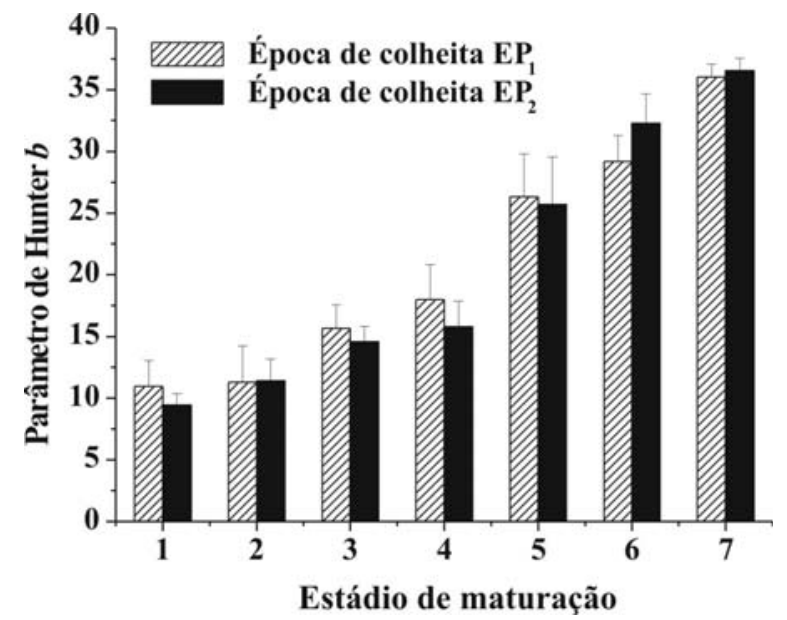

FIGURA 2 -Variação do parâmetro b de Hunter para a região superior próxima ao pedúnculo do maracujáamarelo, em duas épocas de produção (Época $\mathrm{EP}_{1}{ }^{-}$ Maio/Setembro e Época EP 2 - Outubro/Dezembro), em sete estádios de maturação.

\section{CONCLUSÕES}

1-Neste trabalho, determinou-se um padrão de escala de cor para o maracujá-amarelo em diferentes épocas de colheita, contemplando sete estádios de maturação que abrangem todo o período de amadurecimento do fruto.

2-Os frutos da estação de maior temperatura e regime de chuvas $\left(\mathrm{EP}_{2}\right)$ apresentaram rendimento máximo em suco a partir do estádio de maturação com $65 \%$ de coloração amarela da casca. Os frutos da estação de menor temperatura e regime de chuvas $\left(\mathrm{EP}_{1}\right)$ apresentaram máximo rendimento em suco para estádios com 21,3\% de coloração amarela, alcançando valores de até $40 \%$ de rendimento. Os frutos colhidos com, pelo menos, 65,9\% de área da casca amarelada não apresentaram modificação do rendimento em suco, nas duas épocas de colheita. Nos estádios iniciais de amadurecimento, os frutos da época $\mathrm{EP}_{2}$ apresentaram maior espessura de casca e menor rendimento em suco.

\section{AGRADECIMENTOS}

Os autores agradecem ao apoio financeiro da FAPERJ e do CNPq, à CAPES pela bolsa de estudos, e ao Professor Romeu Vianni (in memoriam).

\section{REFERÊNCIAS}

ARJONA, H. E.; MATTA, F. B.; JAMES, O. G. Temperature and storage time affect quality of passion fruit. HortSciense, Alexandria, v. 27, n. 7, p. 809-810, 1992.

CARVALHO, A. J. C.; MARTINS, D. P.; MONNERAT, P. H.; BERNARDO, S. Adubação nitrogenada e irrigação no maracujazeiro-amarelo. I-Produtividade e qualidade dos frutos.
Pesquisa Agropecuária Brasileira, Brasília, v. 35, n. 6, p. 11011108,2000

CRUZ, C. D. Programa GENES - versão Windows 2.1. Viçosa: Editora UFV, 2001.642 p.

DURIGAN, J. F. Colheita e conservação pós-colheita. In: RUGGIERO, C. Maracujá: do plantio à colheita. In: SIMPÓSIO BRASILEIRO SOBRE ACULTURADO MARACUJAZEIRO, 5., 1998, Jaboticabal. Anais... Jaboticabal: Funep, 1998. p. 257-278.

GAMARRA ROJAS, G.; MEDINA, V. M. Variações físicoquímicas do maracujá ácido em função da idade do fruto. Revista Brasileira de Fruticultura, Jaboticabal, v.17, n.3, p. 103-110. 1995.

GAMARRA ROJAS, G.; MEDINA, V. M. Mudanças bioquímicas do suco do maracujá- amarelo em função da idade do fruto. Revista Brasileira de Fruticultura, Jaboticabal, v.18, n.1, p. 75-83, 1996.

HAFLE, M. O.; PEREIRA JUNIOR, E. B.; SOUSA, J. P.; MENDONÇA, V.; ARAÚJO NETO, S. E. Características do maracujá-amarelo (Passiflora edulis Sims f. flavicarpa Deg.) comercializado no Município de Sousa-PB. In: REUNIÃO TÉCNICA DE PESQUISA EM MARACUJAZEIRO, 4., 2005, Planatina. Anais.... Planaltina: EMBRAPA Cerrados, 2005. p.8285

IBRAF. Instituto Brasileiro de Frutas. Disponível em: <www.ibraf.org.br/estatistica/producao>. Acesso em: $01 \mathrm{fev}$. 2008.

ITI TROPICALS. Disponível em: <www.passionfruitjuice.com>. Acesso em: 01 fev. 2008.

MARCHI, R.; MONTEIRO, M.; BENATO, E. A.; SILVA, C. A. R. Uso da cor da casca como indicador de qualidade do maracujáamarelo (Passiflora edulis Sims. f. flavicarpa Deg.) destinado à industrialização. Ciência e Tecnologia de Alimentos, Campinas, v.20, n.3, p. 381-387, 2000.

NASCIMENTO, T. B.; RAMOS, J. D.; MENEZES, J. B. Características físicas do maracujá-amarelo produzido em diferentes épocas. Pesquisa Agropecuária Brasileira, Brasília, v.34, n.12, p. 2353-2358, 1999.

SALOMÃO, L. C. C.; VIEIRA, G.; MOTA, W. F. Tecnologia de colheita e pós-colheita. In: BRUCKNER, C. H.; PICANÇO, M. C. Maracujá: tecnologia de produção, pós-colheita, agroindústria, mercado. Porto Alegre: Cinco Continentes, 2001. p. 283-303.

SILVA, T. V.; RESENDE, E. D.; VIANA, A. P.; ROSA, R. C. C.; PEREIRA, S. M. F.; CARLOS, L. A.; VITORAZI, L. Influência dos estádios de maturação na qualidade do suco do maracujáamarelo. Revista Brasileira de Fruticultura, Jaboticabal, v. 27, n. 3, p. $472-475,2005$. 